ISBN 978-93-84468-80-4

International Conference on Agricultural, Biological and Environmental Sciences

(ICABES-2016)

Pattaya (Thailand) Dec. 14-16, 2016

\title{
The Present Status of Organochlorine Residues in Milk Collected from Market of Faisalabad-Pakistan
}

\author{
Muhammad Wasim Sajid ${ }^{1 *}$, Muhammad Atif Randhawa ${ }^{2}$, Asim Mehmood $^{1}$, Abrar Hussain $^{1}$, Awais \\ Ihsan $^{1}$ and Muhammad Shamoon ${ }^{3}$ \\ ${ }^{1}$ Department of Bio Sciences, COMSATS IIT, Sahiwal-Pakistan \\ ${ }^{2}$ National Institute of Food Science and Technology, University of Agriculture Faisalabad, Pakistan
}

${ }^{3}$ State Key Laboratory of Food Science and Technology, The synergistic Innovation Center of Food Safety and Nutrition, Jiangnan University, Wuxi 214122, Peoples Republic of China

\begin{abstract}
Contamination in milk is more critical as compared to other foods as milk is first diet given to children before they are able to digest solid food. Children have low immunity to combat diseases, so their exposure to pesticide residues is of extreme concern. Lactating animals can be exposed to pesticide residues in several ways such as contaminated feed, contaminated water or direct contact with pesticides. Pesticides are bioaccumulated in different organs of animal and also secreted in milk. Presence of pesticide residues in milk is apprehension for consumers and producers. This study was designed to estimate exposure of population to these contaminants by screening the level of pesticide residues in milk collected from market close to urban population. It was found that no milk sample was found contaminated with DDT, but they were well below its MRL. Milk was also found contaminated with $\alpha$-endosulfan, $\beta$-endosulfan, Endosulfan-sulphate, Endosulfan-sulphate, DDE, $\gamma H C H$ and Dieldrin. Some of samples were exceeded their MRL. This data will be helpful for Pakistan for data collection and regulating rules and regulations.
\end{abstract}

Keywords: Pesticides residues, Milk, Buffalo, Cow

\section{Introduction}

Since the recorded history milk has been an important part of human diet. It is a balance diet, being produced by nature, which provides essential nutrients required by the human. Milk is lacteal secretion by mammary glands of mammals. Milk is given to new born babies as it contain all essential nutrients required for their proper growth before they are capable to intake solid food. Milk contain lipids both saturated and unsaturated, vitamin C, inorganic elements, vitamins, sugars and other nutrients (Mather, 2000). Milk is complete diet which can keep human body healthy, universally used in the initial phases of life and equally important for all age groups, therefore its contamination by contaminants like pesticides and aflatoxins is of extreme apprehension (Goulart et al., 2008). Children can be at more risk of adverse health effects as compared to adult because of their physiological characteristics and weak immune system, since they may be highly exposed to pesticide residues and aflatoxins.

It is a complex colloidal mixture of fat, proteins, minerals, lactose and many other vital components which are present either in suspension or in dissolved form (Baskaya et al., 2006). Besides its countless benefits it has also bear the paramount potential for leading contaminants to the human's diet. Many previous studies have proved the evidences of likely perilous human acquaintance of pesticides residues and aflatoxin M1 through 
milk (Martinsa et al., 201). As milk consumption is reasonably high by human race, principally among the children, therefore risks of milk contamination with pesticides residues also increasing and constantly posing threats for consumer's health.

At small scale level, small farmers mainly contribute towards total milk production in the country. They do not have adequate conditions for the storage of feed/forage on their dairy farms due to economic backwardness. They are using different kind of pesticides on fodder as a protection against pests, ultimately these pesticides residues becomes part of animal body than milk. The conditions at small scale farms often do not meet the standards. This dilemma leads to the incidence of presence contaminants in the feed which ultimately pass onto the milk (Garcia et al., 2003). Pesticides residues presence in milk is alarming situation for all governing authorities and milk producing companies.

In developing countries, condition is very adverse regarding food safety standards especially in use of pesticides on crops, fodder and animals. Due to low management systems farmers are free to use even banned pesticides on crops and feeding animals with contaminated fodder and water. There is need to check the level of contaminants in food products especially milk, which will helpful in regulating rules and law to meet food safety standards.

\section{Materials And Methods}

\section{Milk Sampling}

Fresh milk samples were collected from 10 different farms of Faisalabad within radius of 45-50 km with frequency of 5 samples per farm per season per specie. Each raw milk sample was collected in pre sterilized plastic bottle placed in container with ice cubes and transported to laboratory at University of Agriculture Faisalabad-Pakistan, where milk was stored at $-20^{\circ} \mathrm{C}$ until further analysis.

\section{Pesticide Residues Analysis}

Extraction of pesticides in milk was carried out as described by Kampire et al., (2011) with some modifications. Briefly, after thawing and homogenization $50 \mathrm{ml}$ of milk sample was taken in a centrifuge tube, centrifuged at $5000 \mathrm{rpm}$ for 20 minutes at $4^{\circ} \mathrm{C}$. Upper layer composed of fat was weighed; 1 gram was taken in $250 \mathrm{~mL}$ flask containing $30 \mathrm{~g}$ anhydrous sodium sulphate. To this $200 \mathrm{~mL}$ of petroleum ether was added and shaken. Than petroleum ether was filtered through filter paper containing anhydrous sodium sulphate to remove traces of water. Filtered abstract was evaporated to $1 \mathrm{~mL}$ and taken in $5 \mathrm{ml}$ hexane for clean-up process. It was passed through column containing florisil $10 \mathrm{~g}$ followed by $5 \mathrm{~g}$ anhydrous sodium sulphate. Column was rinsed with $7 \mathrm{ml}$ hexane; fat extract was passed through column eluted with $150 \mathrm{~mL} \mathrm{n}$-hexane. Extract was evaporated with rotary at $40{ }^{\circ} \mathrm{C}$ near $1 \mathrm{~mL}$; it was taken in vial and flushed with nitrogen gas to dryness. The residues was dissolved in methanol and passed through $0.2 \mu \mathrm{m}$ filters in another vial for GC analysis.

\section{Gas chromatography analysis}

The analysis was done on an Agilent Model 6890 Gas Chromatograph equipped with a 63Ni electron capture detector (GC-ECD). Two $\mu \mathrm{L}$ of extract was injected in splitless mode into a a fused silica capillary column (HP-5MS) of $30 \mathrm{~m}$ in length, $0.25 \mathrm{~mm}$ and film coated $0.25 \mu \mathrm{m}$ capillary column, using nitrogen carrier gas with a $1.0 \mathrm{~mL} / \mathrm{min}$ flow rate and the following oven temperature program: $1500 \mathrm{C}$ initial hold for 5 min to $2100 \mathrm{C}$ at $80 \mathrm{C} / \mathrm{min}$ hold for 2 minutes and to $3000 \mathrm{C}$ at $150 \mathrm{C} / \mathrm{min}$, hold for $10 \mathrm{~min}$. The temperature of the detector was 3000C and injector was 2800C. Reference standards of individual organochlorine pesticides used to identify and quantify the residues were obtained from Dr. Ehrenstorfer GmbH, Augsburg, Germany.

\section{Results And Discussion}

Milk inhabits vital position in diet of human beings and is considered a good source of health, it is said to be near to a complete diet. It is a complex colloidal mixture of fat, proteins, minerals, lactose and many other vital components which are present either in suspension or in dissolved form. For centuries, milk and its products are 
regularly taken up by adults and children in their daily diet. Besides its countless benefits, it also bears paramount potential for foremost contaminants to the human's diet. Hence, because of common incidence and injurious health effects of pesticides residues and aflatoxins contamination, it is of great importance and need of the hour to explore pesticide residues detection and quantification in milk in Pakistan.

\section{Results}

The results in Table depicted that milk samples of buffalo and cow dairy farms were found contaminated with organochlorine residues.

Pesticide residues analysis in milk revealed that buffalo milk sample of zone 1, zone 2 and zone 3 markets were found contaminated with $\alpha$-endosulfan with contamination rate of 67,50 and $67 \%$, respectively and varied from 17.10 to $34.00 \mu \mathrm{g} \mathrm{Kg}-1$ while contamination rate of $\alpha$-endosulfan in milk samples of cow was 67,34 and $50 \%$ in zone 1, zone 2 and zone 3 markets, respectively with range of 15.13 to $35.14 \mu \mathrm{g} \mathrm{Kg}-1$. Milk samples of all markets (buffalo and cow) were found contaminated with pesticide residues and were below MRL, however cow milk were found less contaminated as compared to buffalo farms.

The milk samples of buffalo and cow were found contaminated with $\beta$-endosulfan. In buffalo milk; $\beta$ endosulfan was in range of 13.00 to $64.01 \mu \mathrm{g} \mathrm{Kg}-1$ with contamination rate of 67, 50, $100 \%$ in milk samples of zone 1, zone 2 and zone 3, respectively; while in cow milk, $\beta$-endosulfan varied from 12.10 to $62.04 \mu \mathrm{g} \mathrm{Kg}-1$ with contamination rate of $67,34,75, \%$ in milk samples of zone 1, zone 2 and zone 3, respectively. In buffalo milk; out of 15 milk samples collected form zone 1, 12 milk samples (60.88 $\mu \mathrm{g} \mathrm{Kg-1)}$ were above MRL, and 9 milk sample (48.57 $\mu \mathrm{g} \mathrm{Kg-1)} \mathrm{out} 15$ milk samples of zone 3 were above their MRLs (50.00 $\mu \mathrm{g} \mathrm{Kg-1)} \mathrm{however} 7$ cow milk samples of zone $1(57.10 \mu \mathrm{g} \mathrm{Kg}-1)$ out 15 samples were above the MRLs.

The milk samples of all zones (buffalo and cow) were found contaminated with DDE (Dichlorodiphenyldichloroethylene). In buffalo milk, DDE varied from 2.12 to $6.24 \mu \mathrm{g} \mathrm{Kg}-1$ with contamination rate of $100 \%$ in milk samples of all zones; while in cow farms DDE varied from 1.21 to $7.45 \mu \mathrm{g} \mathrm{Kg}-1$ with contamination rate of $100,67,100 \%$ in milk samples of zone 1, zone 2 and zone markets, respectively. However tested milk samples of buffalo and cow were well below MRL of DDE (50.0 $\mu \mathrm{g} \mathrm{Kg}-1)$.

Buffalo and cow milk samples of all zones were found contaminated with $\gamma \mathrm{HCH}$. In buffalo milk $\gamma \mathrm{HCH}$

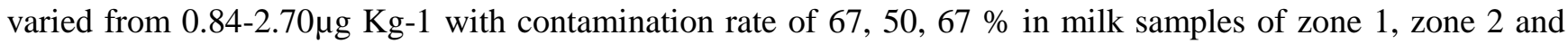
zone 3, respectively; while in cow milk $\gamma \mathrm{HCH}$ varied from 0.87 to $1.91 \mu \mathrm{g} \mathrm{Kg}-1$ with contamination rate of 67 , $67,50 \%$ in milk samples of zone 1, zone 2 and zone 3, respectively. In buffalo milk samples of zone 2 buffalo dairy farm 10 milk samples out of 20 samples, 10 milk samples out of 15 samples in zone 1 and 10 milk samples of zone 3 out of 15 samples exceeded their MRLs $(1.00 \mu \mathrm{g} \mathrm{Kg}-1)$ while in cow farms 10 milk sample out of 20 in zone 3, 10 milk samples out of 15 samples in zone 2 and 8 milk samples out 15 samples in zone 1 exceeded MRL value of $\gamma \mathrm{HCH}$.

Dieldrin was found in milk samples of all types of zones (buffalo and cow). In buffalo milk dieldrin varied from 2.02 to $4.17 \mu \mathrm{g} \mathrm{Kg}-1$ with contamination rate of 67, 75, $67 \%$ in milk samples of zone 1, zone 2 and zone 3, respectively; while in cow farms dieldrin varied from 1.07 to $3.32 \mu \mathrm{g} \mathrm{Kg}-1$ with contamination rate of 67, 67, $50 \%$ in milk samples small, medium and large dairy farms, respectively. Milk samples of buffalo and cow dairy farms were below MRL (20.00 $\mu \mathrm{g} \mathrm{Kg-1)} \mathrm{value} \mathrm{of} \mathrm{dieldrin.}$

Animals raised on fodder/feed contaminated with pesticide residues horde up pesticide residues in edible tissues and secrete them in milk ultimately. Milk which is considered balanced and healthy for all age groups (Grenby et al., 2001; Baskaya et al., 2006) can be contaminated and toxic for human health. The presence and concentration of residues in milk depends on persistency of pesticide residues and nature whether they are hydrophobic or hydrophilic. To check the level of pesticide residues in milk collected from different farms, this study was planned. Analysis of milk collected from different locations has been done by various researchers. Aziz ul Hassan et al. (2014) monitored organochlorine and pyrethroid residues in milk. Pastor et al. (2002) studied pesticide residues in 132 cow milk samples collected from bulk transports (38 samples of raw milk) and market (94 samples of pasteurized milk). 


\section{Discussion}

Organochlorine pesticide residues are highly stable and persistent in nature because of their high density, strong bonding between carbon and chlorine moieties and partitioning behavior under ambient conditions. Due to their high persistent and bioaccumulation these are known as environmental pollutants and their toxic health effects have been identified in animals and humans. The farmer's community especially in the developing countries is mostly illiterate and unaware of the potential hazards of pesticide residue in food. Another reason for presence of pesticide residues in crops/fodder is subtropical climatic conditions prevailing in countries like Pakistan, which results in proliferation of the insects and farmers have to use the pesticides repeatedly to save their crops from insect pests.

Another factor that counts for bioaccumulation of pesticide residues is that less than one percent of the applied pesticide usually reaches the target pest and remaining bulk is left elsewhere in the environment. From the place of application, these pesticides volatilize from soil, enter the atmosphere, re-enter soil and aquatic bodies through precipitation, and also through aerial fall-out. Fodder grown on contaminated soil can accumulate pesticide residues from soil and get contaminated, irrigation of fodder with contaminated water can pollute crop with pesticide residues. Contaminated water, feed and fodder act as main source of entry of pesticides into animals. These pesticides will find their way into meat and milk and may enter the human food chain. The chlorinated pesticides are excreted by animals through their milk fat (Pimentel, 2005; Kampire et al., 2011).

The livestock reared on pesticides contaminated soils, crops, and fodders may accumulate considerable residues in edible tissues. Furthermore, pesticide residues also accumulate on cropland soil. Animals can accumulate these substances from contaminated feed and water. Also, due to the fat-soluble nature of these pesticides, milk and other fat rich substances are the key items for their accumulation (John et al., 2001). Frank et al. (1984) detected fenvalerate residues in two mature holstein cow milk after 3 days application on skin. Milk is an ideal liquid to dissolve environmental contaminants such as pesticides because most of them are fat-soluble.

Organochlorine pesticide residues ( $\alpha$-endosulfan and $\beta$-endosulfan) were detected in milk of cow. The present study is supported by finding of Pietrzak-Fiećko et al. (2014), they reported residual level of $\gamma \mathrm{HCH}$ in cow's milk $22.75 \mu \mathrm{g} / \mathrm{kg}$. Similar findings were reprted by Mocanu et al. (2012), Pardio et al. (2003) and Costabeber et al. (2001).

TABLE I Organochlorine residues in buffalo milk

\begin{tabular}{|c|c|c|c|c|c|}
\hline \multirow[t]{2}{*}{$\begin{array}{l}\text { Pesticides } \\
\text { residues }\end{array}$} & \multicolumn{4}{|c|}{$\begin{array}{c}\text { Buffalo Farms } \\
\left(\mu \mathrm{g} \mathrm{Kg}^{-1}\right)\end{array}$} & \multirow[t]{2}{*}{$\begin{array}{r}\text { MRL } \\
\left(\mu \mathrm{K} \mathrm{Kg}^{-1}\right)\end{array}$} \\
\hline & Range* $^{*}$ & Zone 1 & Zone 2 & Zone 3 & \\
\hline$\alpha$-endosulfan & $17.10-34.00$ & $25.80 \pm 7.00$ & $12.20 \pm 8.04$ & $18.90 \pm 7.11$ & \multirow{2}{*}{50} \\
\hline CR \% & - & 67 & 50 & 67 & \\
\hline$\beta$-endosulfan & $13.00-64.01$ & $60.88 \pm 2.62$ & $14.10 \pm 1.32$ & $48.57 \pm 3.61$ & \multirow{2}{*}{50} \\
\hline CR \% & - & 67 & 50 & 100 & \\
\hline $\begin{array}{l}\text { Endosulfan- } \\
\text { sulphate }\end{array}$ & $7.01-41.00$ & $40.10 \pm 5.01$ & $9.50 \pm 2.13$ & $35.5 \pm 5.35$ & \multirow[t]{2}{*}{50} \\
\hline CR \% & - & 100 & 100 & 100 & \\
\hline DDE & $2.12-6.24$ & $5.20 \pm 0.42$ & $5.18 \pm 1.03$ & $5.30 \pm 0.82$ & \multirow{2}{*}{40} \\
\hline CR \% & - & 100 & 100 & 100 & \\
\hline$\gamma \mathrm{HCH}$ & $0.84-2.70$ & $1.01 \pm 0.32$ & $1.60 \pm 0.71$ & $1.05 \pm 0.46$ & \multirow{2}{*}{1} \\
\hline CR \% & - & 67 & 50 & 67 & \\
\hline Dieldrin & $2.02-4.17$ & $2.10 \pm 0.51$ & $1.44 \pm 1.10$ & $1.50 \pm 0.32$ & \multirow{2}{*}{6} \\
\hline CR \% & - & 67 & 75 & 67 & \\
\hline DDT & ND & ND & ND & ND & \multirow{2}{*}{40} \\
\hline CR \% & - & - & - & - & \\
\hline
\end{tabular}


TABLE II Organochlorine residues in cow milk

\begin{tabular}{|c|c|c|c|c|c|}
\hline \multirow[t]{2}{*}{$\begin{array}{l}\text { Pesticides } \\
\text { residues }\end{array}$} & \multicolumn{4}{|c|}{$\begin{array}{c}\text { Cow Farms } \\
\left(\mu \mathrm{g} \mathrm{Kg}^{-1}\right)\end{array}$} & \multirow{2}{*}{$\begin{array}{c}\text { MRL } \\
\left(\mu \mathrm{g} \mathrm{Kg}^{-1}\right)\end{array}$} \\
\hline & Range $^{*}$ & Zone 1 & Zone 2 & Zone 3 & \\
\hline$\alpha$-endosulfan & $15.13-35.14$ & $16.50 \pm 4.00$ & $32.70 \pm 2.01$ & $21.60 \pm 2.20$ & \multirow{2}{*}{50} \\
\hline CR \% & - & 34 & 67 & 50 & \\
\hline$\beta$-endosulfan & $12.10-62.04$ & $57.10 \pm 1.12$ & $48.40 \pm 4.01$ & $18.40 \pm 4.12$ & \multirow[t]{2}{*}{50} \\
\hline CR \% & - & 67 & 34 & 75 & \\
\hline Endosulfan-sulphate & $8.10-38.00$ & $29.60 \pm 4.00$ & $25.80 \pm 2.34$ & $7.50 \pm 1.03$ & \multirow[t]{2}{*}{50} \\
\hline CR \% & - & 100 & 67 & 50 & \\
\hline DDE & $1.21-7.45$ & $4.16 \pm 0.27$ & $5.44 \pm 0.48$ & $1.90 \pm 0.41$ & \multirow[t]{2}{*}{40} \\
\hline CR \% & - & 100 & 67 & 100 & \\
\hline$\gamma \mathbf{H C H}$ & $0.87-1.91$ & $1.70 \pm 0.10$ & $1.64 \pm 0.21$ & $1.35 \pm 0.40$ & \multirow[t]{2}{*}{1} \\
\hline CR \% & - & 67 & 67 & 50 & \\
\hline Dieldrin & $1.07-3.32$ & $2.25 \pm 1.00$ & $2.35 \pm 0.45$ & $1.68 \pm 0.32$ & \multirow[t]{2}{*}{6} \\
\hline CR \% & - & 67 & 67 & 50 & \\
\hline DDT & $\mathrm{ND}$ & ND & ND & ND & \multirow{2}{*}{40} \\
\hline CR \% & - & - & - & - & \\
\hline
\end{tabular}

\section{References}

[1] Aziz ul Hassan, A. B. Tabinda, M. Abbas and A. M. Khan . 2014. Organochlorine and pyrethroid pesticides analysis in dairy milk samples collected from cotton growing belt of punjab, pakistan. Pak. J. Agri. Sci. 51(2):331-335.

[2] Baskaya, R., A. Aydin, A. Yildiz and K. Bostan. 2006. Aflatoxin M1 levels of some cheese varieties in Turkey. Med. Weter. 62:778-780.

[3] Costabeber, I., R. Trindade and L. M. Fries. 2001. Residuos de DDE, HCB, heptaclorepo xido y lindano en leche UHT comercializada en Santa Marı'a, RS.ILE - IndustriasLacteasEspan olas. 259:42-47.

[4] Frank, R., H.E. Braun, L.A. Miller and G.W. Allan. 1984. Fenvalerate residues in milk following topical treatments to dairy cows. Pesticide sci.15(6):600-604.

https://doi.org/10.1002/ps.2780150611

[5] Garcia, O., K. Mahmood and T. Hemme. 2003. A review of milk production in Pakistan with particular emphasis on small-scale producers. PPLPI Working Paper No.3. Rome: Food and Agriculture Organization of the United Nations.

[6] Goulart, S.M., M.E.L.R. de Queiros, A.A. Neves and J.H. de Queiros. 2008. Low-temperature clean-up method for the determination of pyrethroids in milk using gas chromatography with electron capture detection. Talanta. 75:1320-1329. https://doi.org/10.1016/j.talanta.2008.01.058

[7] Grenby, T.H., A.T. Andrews, M. Mistry and R.J.H. Williams. 2001. Dental caries-protective agents in milk and milk products: investigations in vitro. J. Dentistry 29:83-92.

https://doi.org/10.1016/S0300-5712(00)00061-0

[8] John, P.J., N. Bakore and P. Bhatnagar. 2001. Assessment of organochlorine pesticide residue levels in dairy milk and buffalo milk from Jaipur City, Rajasthan, India. Environ. Int. 26(4):231-236.

https://doi.org/10.1016/S0160-4120(00)00111-2

[9] Kampire, E., B.T. Kiremire, S.A. Nyanzi and M. Kishimba. 2011. Organochlorine pesticide in fresh and pasteurized cow's milk from Kampala markets. Chemosphere. 84:923-927.

https://doi.org/10.1016/j.chemosphere.2011.06.011 
[10] Martinsa, J.G., A.A. Chavez, S.M. Waliszewski, A.C. Cruz and M.M.G. Fabila. 2013. Extraction and clean-up methods for organochlorine pesticides determination in milk. Chemosphere. 92:233-246.

https://doi.org/10.1016/j.chemosphere.2013.04.008

[11] Mather, I.H. 2000. A review and proposed nomenclature for major proteins of the milk-fat globule membrane. J. Dairy Sci. 83:203-247. https://doi.org/10.3168/jds.S0022-0302(00)74870-3

[12] Mocanu, G.D., O.V. Nistor, E. Botez, D.G. Andronoiu and V.M. Macovei. 2012. Trace elements and organochlorine pesticides in raw milk from south eastern regions of Romania. J. Food Sci. Eng. 2:143-148.

[13] Monit. 12(10):1864-1875.

[14] Pardio, V.T., K.N. Waliszewski, L.A. Landin and R.G. Bautista. 2003. Organochlorine pesticide residue in cow's milk from a tropical region of Mexico. Food Addit.Contam. 20:259-269.

https://doi.org/10.1080/0265203021000046207

[15] Pastor, C.H., A.B. Gebara and H. de Souza Spinosa. 2002. Pesticide residues in cow milk consumed in Sao Paulo City (Brazil). J Environ. Sci. Health, Part B. 37(4):323-330. https://doi.org/10.1081/PFC-120004473

[16] Pietrzak-Fiećko, R., M, Gałgowska, S. Bakuła and B. Felkner-Poźniakowska. 2014. Chlorinated hydrocarbons residues in milk fat of selected farm animals from the north-eastern part of Poland. Bull. Veterinary Ins. Pulawy. 58:71-75.

https://doi.org/10.2478/bvip-2014-0011 